\section{Bringing Back the Brains}

WHEN the North American Joint Selection Board started recruiting in the United States and Canada ten years ago, it was well ahead of the fashion. Since then, the board has brought back more than 500 British scientists, the most effective effort to reverse the brain drain yet made, despite the arrival of other agencies in the field. The cost of the operation-about $£ 500$ per man recruited-is little more than it costs to recruit inside Britain.

The chairman of the board, Mr H. S. Hoff, is an unexpected man to find in charge. Some of the scientists he has recruited have been surprised to be interviewed by a novelist (better known as William Cooper); others have been irritated at being interviewed at all. The Ministry of Technology's efforts to publicize the brain drain have created the impression that British scientists abroad have only to ask in order to be welcomed back; in fact, the number of jobs available is always likely to limit the process.

The board is responsible for recruiting for the Scientific Civil Service, the Atomic Energy Authority and the Central Electricity Generating Board. This is done by a combination of advertisements (in such publications as Nature, the Guardian Weekly and the Observer) and letters from the chairman, followed up by a series of personal interviews. These are intensive and demanding, carried out by a board of four or five chaired by Mr Hoff, and scientists with several publications to their credit sometimes find them rather an affront to their dignity. But the board is looking for the sort of people who can generate ideas, who are more than mere technicians with a facility for doing experiments. The board recruits at the level of scientific officer, senior scientific officer and sometimes recommends appointments as research fellows. The board's reports, ruthlessly honest documents which assess candidates on an alpha, beta, gamma scale, are sent to possible research establishments with the other documentation-enquiry form, list of publications, and professional references. For a recommendation as scientific officer or senior scientific officer, the candidate must score beta plus ; for a research fellowship, alpha.

Over the years, the board has gathered a certain amount of folklore around it. One of the rumours in North America is that the board turns down 90 per cent of those who apply-quite untrue, as last year 58 per cent were approved for the scientific officer or research fellowship classes. Something like one third of the total number recommended actually accepted appointments in Britain. Although the numbers are small, they make up a major part of the annual recruitment in these classes for all three participants in the scheme. Unsuccessful candidates or those who are successful in the interviews but cannot be fitted into any of the establishments can, if they wish, have their application form (but not the confidential report) sent to Management Selection Ltd, which is employed by the Ministry of Technology to bring back scientists to Britain.

Such evidence as there is suggests that people recruited by the board tend to stay in Britain once they get back. A survey of research fellows appointed at Harwell showed that the turnover of those recruited in the United States was lower than those recruited locally. Mr Hoff is not surprised by this-people who go to the trouble of getting in touch with the board are probably serious in their intentions. Naturally, the odd one or two who do decide to go back to the US get very much more publicity than the hundreds who decide to stay.

The numbers wanting to come back have been growing during the past few years. In 1966, 188 presented themselves for interview; last year it was 215, this year 249. Mr Hoff is wary of generalizing from this; it might simply be a reflexion of the rate at which traffic in the other direction has been growing. Candidates themselves usually say that there is "no single reason" for their wanting to come back. "It's a lot of intangibles." In any case, as Mr Hoff points out, scientists trained to be analytical "are not given to analysing their own motives". But there is evidence that political developments in the United States have begun to worry some immigrant scientists. "They're dismayed by the general climate", Mr Hoff says. The Vietnam war and violence in the streets have now been added to the standard clichés about materialism, the absence of culture and the pressure to publish. Domestic reasons like aged parents or children's education still count for a lot, of course. Britain's economic problems do not seem to put people off.

The operation, of course, is on a very small scale compared with the problem. In 1966, when the Hoff mission brought back about 50 people, nearly 2,000 scientists emigrated (though the quality of the returning group was higher). The chances are that the work of the board could not easily be extended and its results made available to industry - this would mean, $\mathrm{Mr}$ Hoff believes, that the mission would lose "the personal touch" on which it prides itself.

\title{
Slower Pace of Growth in France
}

from our Paris Correspondent

Paris, November

THE new Research Minister, M. Robert Galley, is to outline his policy and defend his budget before the House of Deputies on November 18. Nobody expects fiery exchanges of oratory. Out of 500 deputies, only 15 or 20 at the most are usually present during this kind of debate. A few opposition members will each year offer some criticism, but their lack of knowledge 